\title{
Heat Transfer Validation and Comparative Evaluation of Biochar Yield from Pyrolysis Cook Stove
}

\author{
Teka Tesfaye Mengesha ${ }^{1}$ and Ancha Venkata Ramayya ${ }^{2}$ \\ 1. Oromia Agricultural Research Institute, Jimma Agricultural Engineering Research Center, P.O. Box 386, Jimma, Ethiopia \\ 2. Jimma University Institute of Technology, P.O. Box 378, Jimma, Ethiopia
}

\begin{abstract}
The developing world still largely depends on biomass, such as wood, animal dung and agricultural waste for domestic fuel sources that are typically burned in traditional stoves. Ethiopia has different biomass resource for biochar production, through pyrolysis cook stove co-producing biochar. Coffee husks are the major solid residues from the handling and processing of coffee in the study area. This study was to evaluate the biochar co-producing pyrolysis cook stove with respect to heat transfer through the bed and biochar yield. From allothermal type of pyrolysis cook stove, the stove design was selected for both the computational fluid dynamic (CFD) simulation and experimental measurements. ANSYS 14.5 was used for CFD simulation of the wood combustion. The production of biochar from coffee husk, corncob and sawdust at different heating times, bed and stove surface temperature were undertaken. Bulk density, $\mathrm{pH}$ and surface area of the biochar were measured. While good agreement between simulation and experimental result was obtained in the conduction phase during pyrolysis, deviation between the two on account of the effect of volatile gas in changing the temperature trend within the biomass bed was noticed. Within the biomass type, the maximum mean biochar yield (38.91\%) was seen from coffee husk. In the case of different stove designs, the minimum mean biochar yield (27.11\%) was found from normal Anila stove. The $\mathrm{pH}$ of biochar is found to be significantly affected by the type of biomass (9.83 mean for corncob and coffee husk, 6.43 mean for sawdust), heating time (9.19 mean for 90 min and 8.01 mean for 30 min) and stove type (9.52 mean for normal Anila and 8.01 mean for flangeless Anila continuous feeding type). In fact, the type of biomass is observed to significantly affect the bulk density and surface area of biochar.
\end{abstract}

Key words: Biochar, temperature, cook stove, biomass, pyrolysis, soil, CFD simulation.

\section{Introduction}

For any biochar colonizing soil bacteria, biochar assists as a source of reduced carbon compounds [1] and is also suitable for using as a soil betterment and fertilizer [2]. Biochar adsorbs both nutrients and organic contaminants effectively [3]. It also improves soil by increasing soil organic matter, soil $\mathrm{pH}$, exchangeable potassium (K), exchangeable calcium (Ca), total phosphorus (P) and cation exchange capacity (CEC), and decreasing soil strength, exchangeable aluminium (Al), soil bulk density and soluble iron (Fe) [4].

The efficiency of mineral nitrogen $(\mathrm{N})$ fertilizer is improved by soil charcoal amendments [5]. Via ion exchange, biochar can take up and supply $\mathrm{N}$ to

Corresponding author: Teka Tesfaye Mengesha, M.Sc., research field: energy engineering. biomass, and the most promising views are the development of slow-released $\mathrm{N}$ fertilizers [6].

Biochar stimulates immobilization and mineralization with flow on consequences for nitrite $\left(\mathrm{NO}_{3}{ }^{-}\right)$leaching and reduce ammonia $\left(\mathrm{NH}_{3}\right)$ via adsorption [6]. Study indicated that cumulative $\mathrm{P}$ and $\mathrm{K}$ release have contradictory associations with biochar [7].

Water-holding capacity and water available for crop use were increased by adding biochar to the soil [8]. Because of its high porous structure, biochar potentially is responsible for increasing soil surface area, improving water retention [9] and improving water quality [3]. A comparision among the thermal conversion technologies shows that gasifier-produced biochar has higher crop yields than kiln-produced biochar when added to the soil [10].

The large potential for climate change mitigation of 
biochar produced from gasification was clearly demonstrated through the life cycle analysis (LCA) study [11]. Since pyrogenic carbon is formed by pyrolysis, the biochar proved to be stable and effective carbons sink. Hence, it stays in the soil for long durations. The carbon locked in soil do not get released as $\mathrm{CO}_{2}$ due to the microbial activity. However, the carbon in the biomass is subjected to easy degradation, since they contain low grade carbon [1, 2]. The effect of the biomass type was seen by comparing kiln-produced chars from different feedstocks, and the coffee husk chars were the most productive [10]. Also, in a different study, usage of agricultural leftover materials as sole biochar feedstock was recommended [12].

All biochars do not have identical properties, since their characteristics are controlled by factors, such as pyrolysis conditions (pyrolysis temperature, rate of heating), feedstock type and duration of charring. The fitness of biomass for this application is dependent on a number of physical, environmental, chemical, as well as economic and logistical factors. Knowledge of pyrolysis reaction conditions, biochar properties and soil response to biochar amendments can be used to design an optimum biochar for a given area depending on its feedstock availability and soil needs. Biochar is characterized by molecular structure (such as, porosity and surface area), organic carbon content, ash content, $\mathrm{pH}, \mathrm{CEC}$ and nutritional value in terms of NPK.

Biochars with lower total surface charges but higher surface areas, $\mathrm{pH}$ and ash contents were observed to be produced at higher pyrolysis temperatures. These biochars also had higher percentage of carbon (C), but much lower hydrogen and oxygen contents [13]. The biochars varied much in their characteristics [1]. The chemical properties of biochar and its net effect when added to soils were influenced by feed stock, pyrolysis temperature and speed, post handling and storage conditions [14]. An increased release of volatiles as a result of increased pyrolysis temperatures resulted in higher fractions of stable $C$ and total $C$ [15]. Compared to the heating rate, temperature had a pronounced influence on the biochar yield [16].

As the biochar production temperature increases, the retention of water and nutrient by biochar showed an increasing trend. Shafie et al. [17] agreed that $400{ }^{\circ} \mathrm{C}$ is the appropriate temperature to produce quality biochar. For obtaining higher calorific value and the maximum fixed carbon percentage, indirect method is more suitable for carbonization than direct method [18]. The mass of the biomass reduces as the pyrolysis temperature increases, i.e., at $500{ }^{\circ} \mathrm{C}$ more biochar yield is observed as compared to $600{ }^{\circ} \mathrm{C}$ and $700^{\circ} \mathrm{C}$. At higher temperatures, biochars produced are relatively alkaline in nature [19]. Higher temperature biochars have higher surface area and more micropore volumes than those of lower temperature biochars [20]. Higher heating value and $\mathrm{pH}$ of biochar solution was correlated with pyrolysis temperature [21].

The objective of this study was to evaluate the impact of transient heating on the biochar yield of selected indirect type pyrolysis cook stove designs using computational fluid dynamic (CFD) simulation and experimentation.

\section{Materials and Methods}

\subsection{Stove Description}

The Anila stove is a simple technology for converting biomass to char at household level. The stove has been designed and built by Dr. Ravi Kumar of the Mysore University in India. The stove consists of two metal barrels. The outer barrel is filled up with biomass and the inner is with firewood. After burning the fire wood for $30-40 \mathrm{~min}$, the pyrolysis of the biomass starts.

Fig. 1 shows four indirect type stoves that were used for the experiment:

(1) Continuous feed flange less Anila stove (S1) - Anila stove was modified to make the fuel feed (wood) continuous, reduced height and increased outer diameter without flange, and the lid simply put at the top and the vessel rest on the lid; 


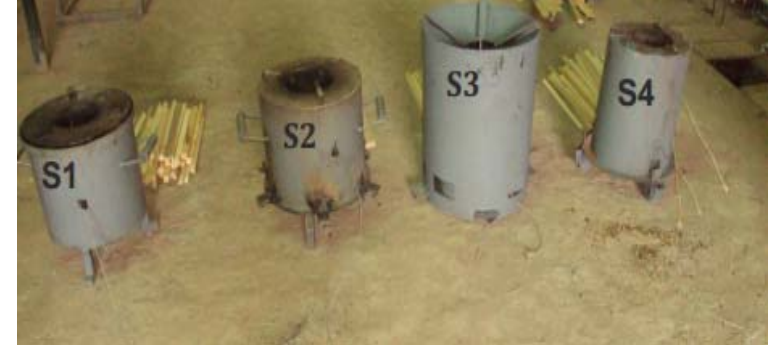

Fig. 1 Allothermal stove type.

(2) Continuous feeding Anila type stove (S2) —Anila stove was modified to make the fuel (wood) continuous, reduced height and increased outer diameter with flange tightened at six place using bolt and nut;

(3) Cornel design stove (S3) — this stove design was taken from Cornell University, USA. The stove has an outer shell for secondary air and pot rest, pyrolysis chamber with legs and pyrolysis chamber lid for protecting syngas leakage;

(4) The normal Anila stove (S4).

\subsection{Biochar Yield and Temperature Measurement}

Potential feedstocks selected for biochar production are sawdust, coffee husk and corncob. Each of the selected stove design is used for th temperature (> $500{ }^{\circ} \mathrm{C}$ ) with 30,60 and 90 min charring time.

To measure the temperature within the biomass bed, point is marked on the outer surface of the stove 30 $\mathrm{cm}$ from ground and drilled to insert type $\mathrm{J}$ thermocouple wire up to the center. Then the drilled part of the outer surface of the stove was sealed using epoxy.

The inner and outer surface temperature of the stove was measured using infrared temperature measuring device by selecting a similar region on each surface of the stoves per 10 min interval for all testing conditions. For each condition, the mass of biomass, wood consumed and biochar produced were measured using digital balance of $0.1 \mathrm{~g}$ precision. The biochar produced was stored in the storage place by giving a code.

\subsection{Numerical Simulation}

ANSYS 14.5 work bench was used for simulation of wood combustion. ANSYS design modeler was used for stove geometry by selecting one indirect type stove design. Fig. 2 shows the sectional view of the selected stove design.

The biomass bed was thermally coupled to the combustion part for heat transfer.

The value of the specific heat capacity was taken from Refs. [22-26] for each biomass, and the effective thermal conductivity was calculated using geometric mean model for defining the biomass feedstocks.

The data required at a boundary depends up on the boundary condition type and the physical models employed. Convection loss was considered for the outer surface of the stove using the wind speed data for study location. Standard initialization methods were

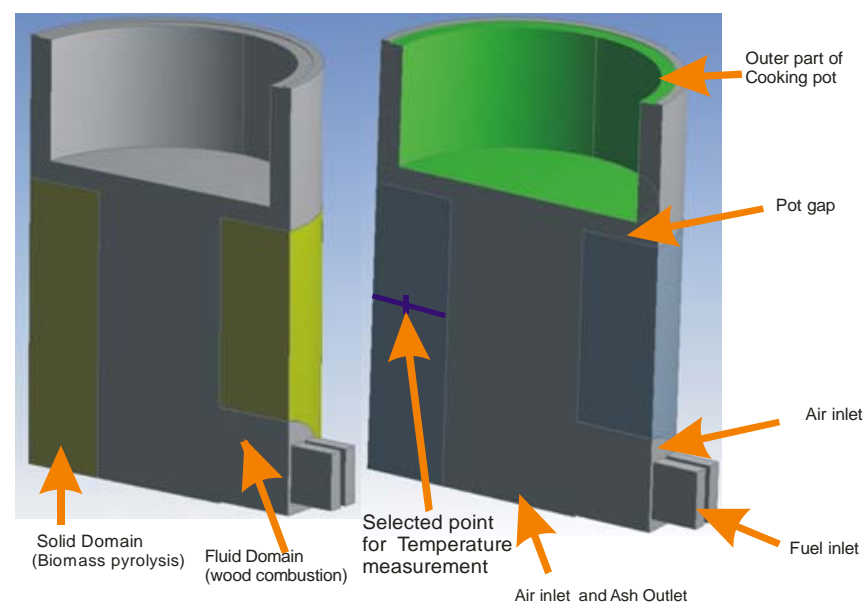

Fig. 2 Sectional view of stove design for CFD simulation. 
used with initial values of $1 \mathrm{~m}^{2} / \mathrm{s}^{2}, 1 \mathrm{~m}^{2} / \mathrm{s}^{3}$ and 300 kelvin (K) for specific turbulent kinetic energy, specific turbulent dissipation rate and temperature, respectively.

Species volumetric reaction with inlet diffusion was used. The eddy dissipation model was applied to turbulent flows, when the chemical reaction rate is fast relative to the transport processes in the flow. There is no kinetic control of the reaction process. By default, for the eddy dissipation model, it is sufficient for fuel and oxidant to be available in the control volume for combustion to occur.

The geometry was discretized with the same type of element for both solid and fluid domain, but with different element size.

\subsection{Biochar Testing}

The following testing parameters were undertaken directly for biochar made from coffee husk and sawdust biomass. However, biochar made from corncob was crushed to small size for measuring the parameters.

\subsubsection{Biochar $\mathrm{pH}$}

Standardized product definition and product testing guidelines for biochar use in soil developed through International Biochar Initiatives were used for biochar testing. Each produced biochar was mixed and samples was taken.

Biochar $\mathrm{pH}$ values were obtained using a ratio of $1.0 \mathrm{~g}$ of biochar in $20 \mathrm{~mL}$ deionized water with shaking for $1.5 \mathrm{~h}$, using a shaker to ensure sufficient equilibration between solution and biochar surfaces [27].

\subsubsection{Biochar Surface Area}

Surface area per gram of the biochar was obtained using Sears method 1956 [28]. A biochar sample of $1.5 \mathrm{~g}$ was mixed with $100 \mathrm{~mL}$ of water and $30 \mathrm{~g} \mathrm{NaCl}$. The mixture was stirred for $5 \mathrm{~min}$, and $0.1 \mathrm{~N} \mathrm{HCl}$ was added to make final volume $150 \mathrm{~mL}$ and final $\mathrm{pH}$ as 4.0. It was then titrated against $0.1 \mathrm{~N} \mathrm{NaOH}$. The volume $(\mathrm{mL})$ of $0.1 \mathrm{~N} \mathrm{NaOH}$ required to raise the $\mathrm{pH}$ from 4.0 to 9.0 was noted. The specific area $\left(\mathrm{m}^{2} / \mathrm{g}\right)$ was obtained from Eq. (1):

$$
A=32 V-25
$$

where, $A$ = surface area of carbon per gram $\left(\mathrm{m}^{2} / \mathrm{g}\right) ; V$ = volume of $0.1 \mathrm{~N} \mathrm{NaOH}$ required to raise the $\mathrm{pH}$ from 4.0 to 9.0 .

\subsection{Method of Processing and Analysis of Data}

The data were analyzed using simple statistical tool and SPSS. The significance of the independent variables was checked using ANOVA. The mean difference was done using LSD for significant factors.

\section{Results and Discussion}

\subsection{Measured Temperature during Biochar Production}

Fig. 3 shows the trend of temperature with time at different position of the Anila stove during charring of the selected biomass. The average inner surface temperature of the stove during biochar production using the biomasses (coffee husk, sawdust and corncob) was tried to control by changing the rate of feeding of the fuel to make the reading unfluctuating within the test duration. The data were taken per 10 min interval within $1.5 \mathrm{~h}$ test duration, and the average of the first three 10 min interval was calculated and tabulated. Fig. 3 clealy shows the influence of the inner surface temperature, the effect of void fraction and particle density on the packed bed and outer surface temperature of the stove.

The temperaure due to heat transfer within the biomass bed from inner surface to outer surface was seen at selected point between the two surfaces in the packed bed. For a given biomass, the higher temperature on the inner surface of the stove gives higher temperature reading in the biomass bed.

In the case of coffee husk biomass, temperature in the bed shifts more to the inner surface temperature. But for corncob biomass, the outer surface temperature reading is the highest, this may be due to the void fraction which facilitates the volatile gas movement. Packed bed of large particles are more porous than 


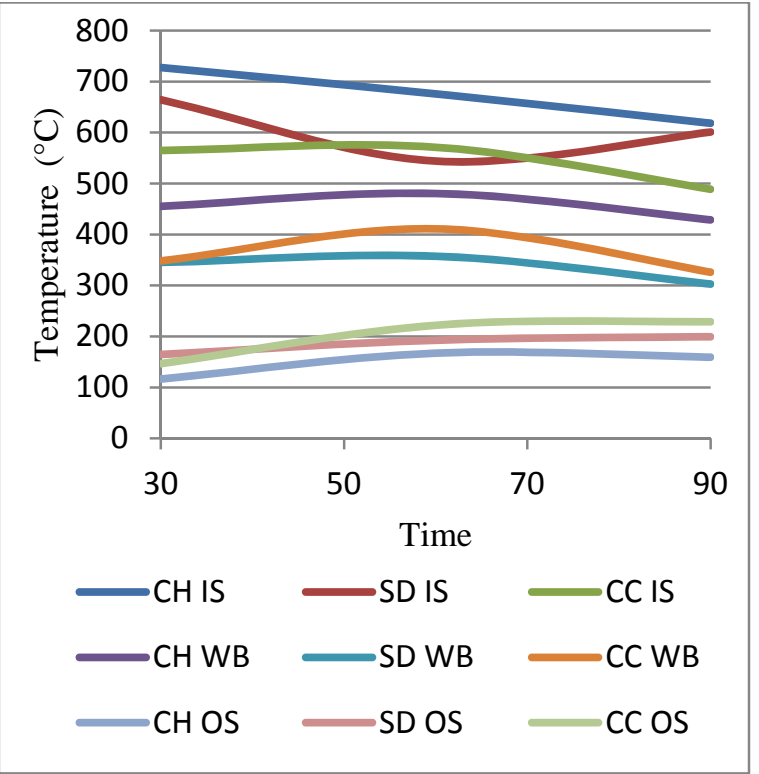

Fig. 3 Trend of temperature with time for the biomasses using Anila stove.

$\mathrm{CH}$ : coffee husk, SD: sawdust, CC: corncob, IS: inner surface, OS: outer surface, WB: biomass bed.

packed bed of small particles. So the gas temperature in the bed became lower as the particles became smaller [29].

It has been observed that the heating dynamics and conversion time of biomass pyrolysis vary with the properties of the packed bed and are also different for the same shape and size of the bed. These results are understandable on the basis of changes induced in the bulk density and presumably the effective thermal conductivity of the sample. As a result, variations are observed in the bulk density, the void fraction and presumably the thermal conductivity of the samples, heat and mass transfer rates. Generally, higher densities appear to reduce the heating rate and the spatial gradients of temperature [30].

As the external heating conditions are made more severe, spatial gradients of temperature tend to increase so that the effects of the reaction energetics remain visible over a successively thin core of the bed. The more internal zone of the bed is heated very rapidly, whereas for the more external zone, after an almost linear increase where chemical reactions are not active, the temperature shows some changes in the rising rate to attain a maximum well above the final steady value. Hence, the thermal effects due to chemical reactions tend to become constant [31].

One important aspect in heat transfer is that, as the thermal conductivity of biomass is too low and given the reliance on gas-solid heat transfer, biomass particle size has to be changed to fulfill the requirement of rapid heating [32].

\subsection{Comparison of Experimental and Simulation Result}

The design of the stove with the cooking pot and pot gap for the sake of simulation was cut into half (half section) to reduce the time of convergence for the selected mesh size and to observe the temperature increase due to heat transfer within the biomass packed bed and to the cooking pot. Fig. 4 shows the temperature gradient in the biomass packed bed of the symmetrical view. The heat transfered from the inner surface which is around the maximum $845 \mathrm{~K}$ to the outer surface which is around the minimum $361.6 \mathrm{~K}$. Similarly, by observing the heat distribution on the surface of the cooking pot, the maximum temperature was seen at the bottom center of the cooking pot.

The temperature reading at selected point with heating time of up to 90 min taken per 10 min interval for both the experimrnet and the simulation of coffee husk biomass can be seen in Fig. 5. Up to 20 min, the temperature within the bed for both experiment and simulation case was almost the same. But, because of the movement of volatile gas, the temperature reading
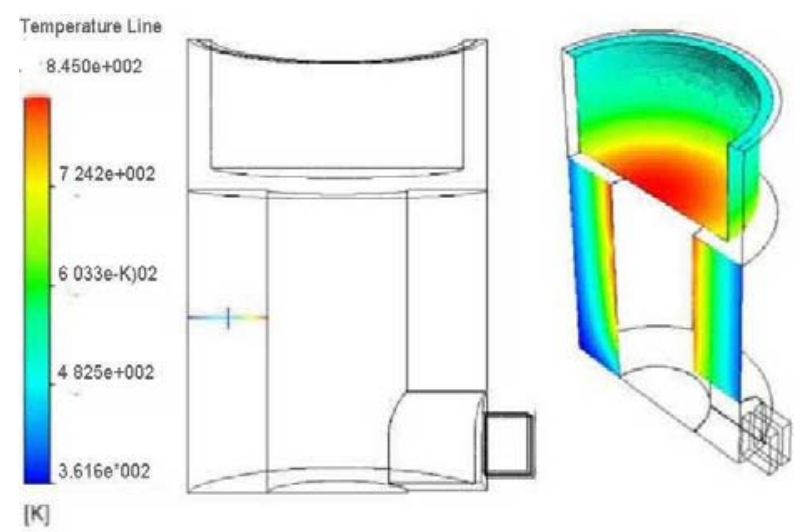

Fig. 4 Heat transfer within the biomass bed at selected locations and to pot. 


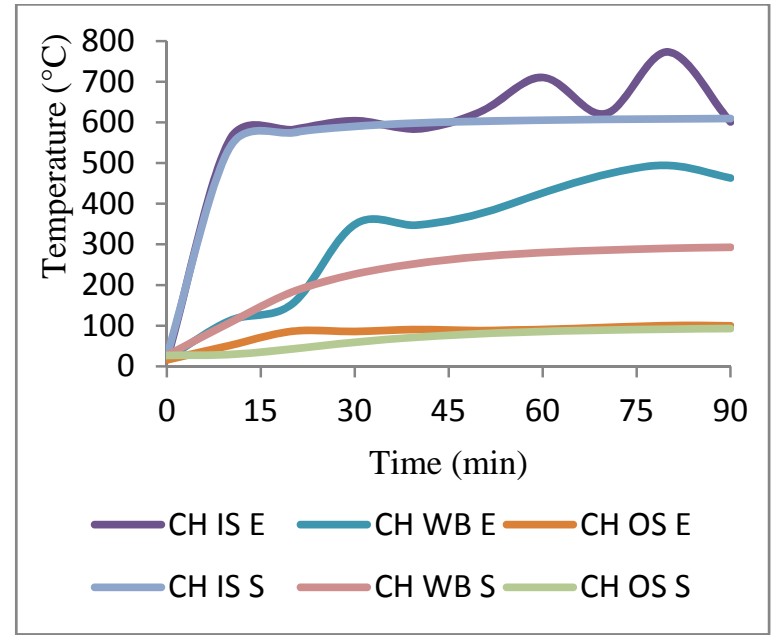

Fig. 5 Trend of temperature with time for coffee husk biomass.

E: experimrnet, S: simulation.

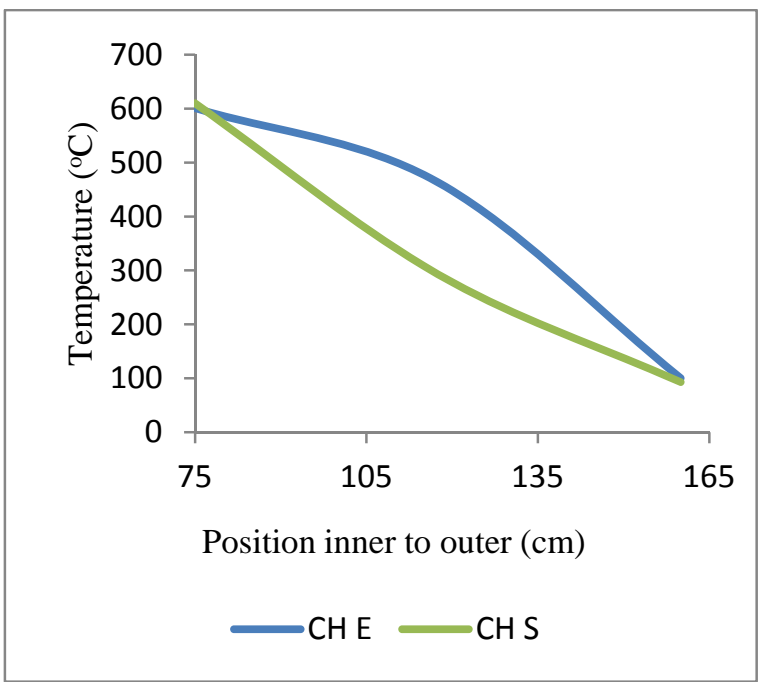

Fig. 6 Heat transfer from inner to outer surface for coffee husk.

of the experiment highly deviated from the simulation one after $20 \mathrm{~min}$ of charring time.

Observing the result of temperatue across the packed bed from inner to outer surface as shown in Fig. 6, experimental observation is seen to be greater through out the biomass bed. This again can be attributed to the movement of volatile gas.

In the case of sawdust (Fig. 7), the experimental temperature was seen to be deviating from the simulated one immediately after $10 \mathrm{~min}$ for both temperature reading in the biomass bed and that of outer surface of the stove. The differences between the feedstocks come in to play due to the void fraction and the particle density changes.

The effect of effective thermal conductivity was clearly shown in Fig. 8, where the sawdust biomass bed acts like an insulator increasing the inner surface temperature by not conducting the heat into the biomass bed.

\subsection{Biochar Yield}

Char is created mostly from the thermal decomposition of lignin and some extractive part of biomass, while the volatile matter is transformed into the gas phase and minerals in the biomass are left as ashes. Hence, at the same heating rate and the residence time, the pyrolysis temperature is the most influential factor for the product distribution [33].

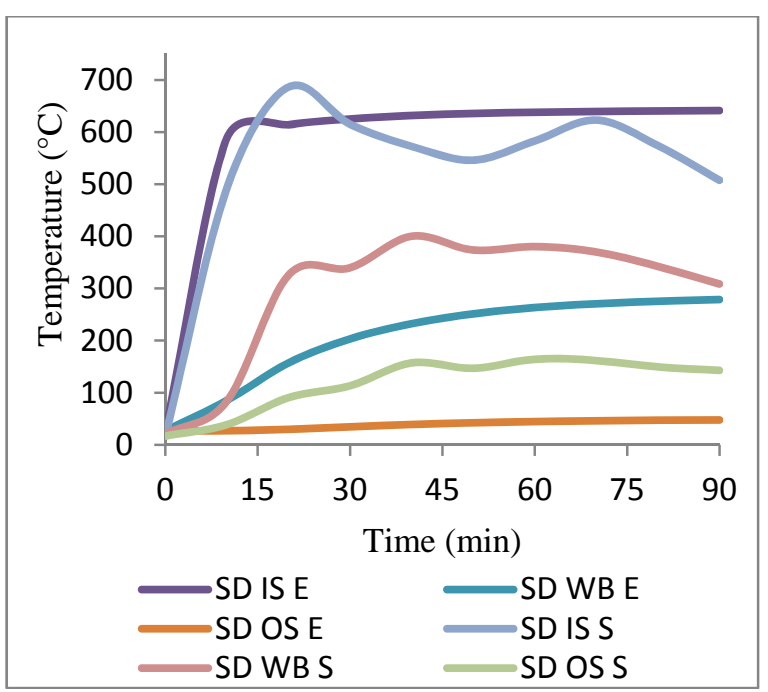

Fig. 7 Trend of temperature with time for sawdust biomass.

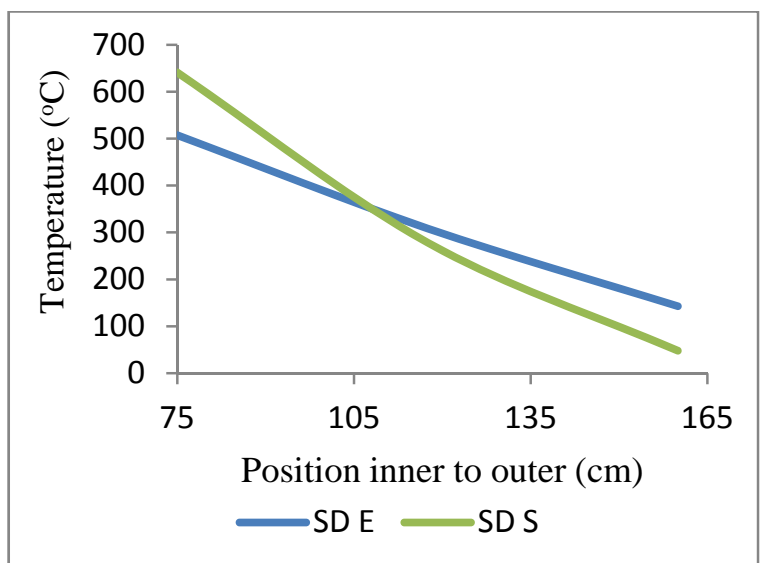

Fig. 8 Heat transfer from inner to outer surface for sawdust. 
The increased yield of gas and liquid probably was derived from the volatilisation of the volatile matters within the biomass as the temperature increased, leading to a decrease of biochar yield. For the same feedstock, biochar yield is highly dependent upon the conditions, under which pyrolysis is carried out, namely, temperature, heating rate, heating time and particle size [34].

Figs. 9-11 indicate the percentage of biomass weight loss with pyrolysis time. From the result, the rate of increment in weight loss begin to decrease after $1 \mathrm{~h}$. This is typical for lignocellulosic materials, for which the devolatilisation rate depends strongly on the reaction temperature and the rapid release of volatiles starts at temperatures as low as $200{ }^{\circ} \mathrm{C}$. This is likely due to the impact of the decomposition of cellulose, which decomposes quickly [35].

The decrease in the solid yield with the increasing temperature and charring time could be due to greater primary decomposition of the sample at higher temperature [36]. There is a possibility that an intermediate reaction occurred during the pyrolysis process, which converted biomass into large amount of other products (liquid and gases) rather than totally transformed into solid (char) product. Yields of liquid products are maximized in conditions of low temperature, high heating rate and a short gas residence time, whereas a high temperature, low heating rate and long gas residence time would maximize yields of fuel gas [17]. It is reported by Devi and Saroha [37] that biochar yield produced from biomass decreased with increase in pyrolysis temperature and the maximum yield was observed at $300{ }^{\circ} \mathrm{C}$.

As seen in Fig. 9, the rate of biomass weight loss was rapidly increasing for S3 and S4. This may be due to the difference in stove design of the outer diameter is large for S1 and S2 and because of the bulk density of the coffee husk compared to saw dust and corn cob in Figs. 10 and 11.

From the statistical level of significance perspective
(Table 1), inferred from ANOVA, both biomass type and stove are not observed to significantly affect biochar yield.

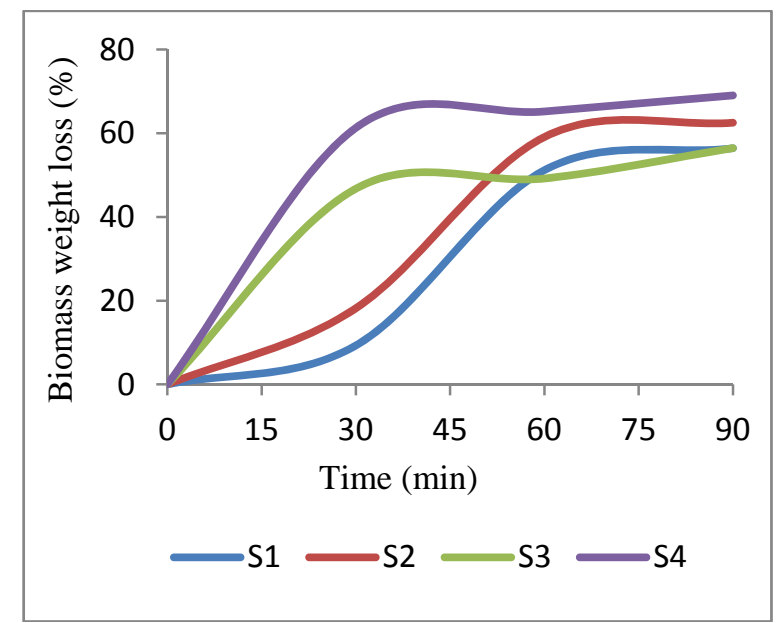

Fig. 9 Conversion of coffee husk to biochar.

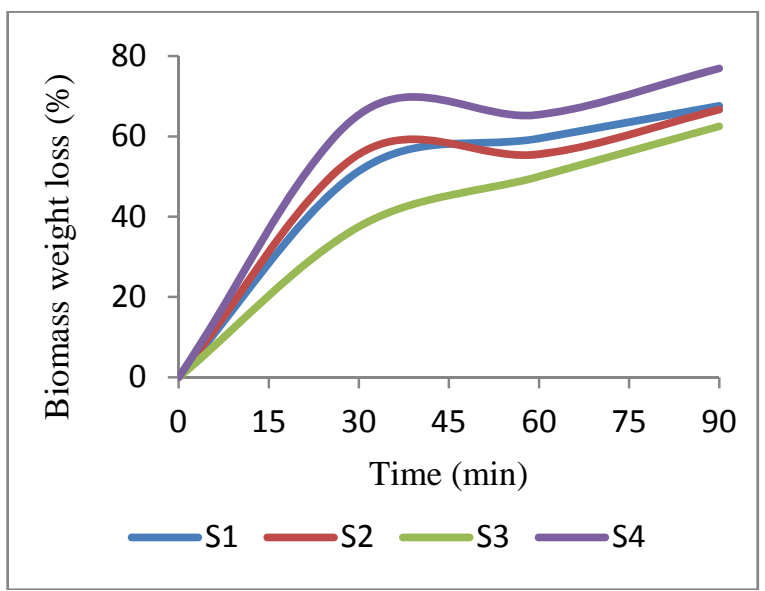

Fig. 10 Conversion of sawdust to biochar.

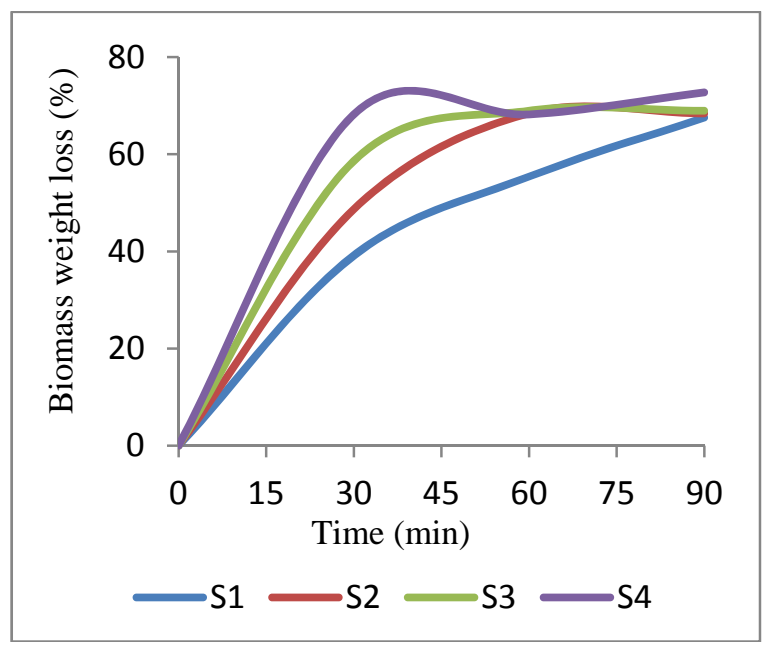

Fig. 11 Conversion of corncob to biochar. 
Table 1 Statistical result of biochar yield in \%.

\begin{tabular}{ll}
\hline Variables & Yield \\
\hline Biomass & \\
\hline Coffee husk & $38.91 \pm 3.01$ \\
Sawdust & $31.59 \pm 3.04$ \\
Corncob & $31.87 \pm 1.83$ \\
\hline Stove & \\
\hline S1 & $36.16 \pm 3.72$ \\
S2 & $34.14 \pm 1.76$ \\
S3 & $39.09 \pm 2.26$ \\
S4 & $27.11 \pm 2.28$ \\
\hline
\end{tabular}

For biomass, results are means of four observations and for stove are means of three observations.

Means \pm standard error of the results are not significantly different from each other at $P<0.05$.

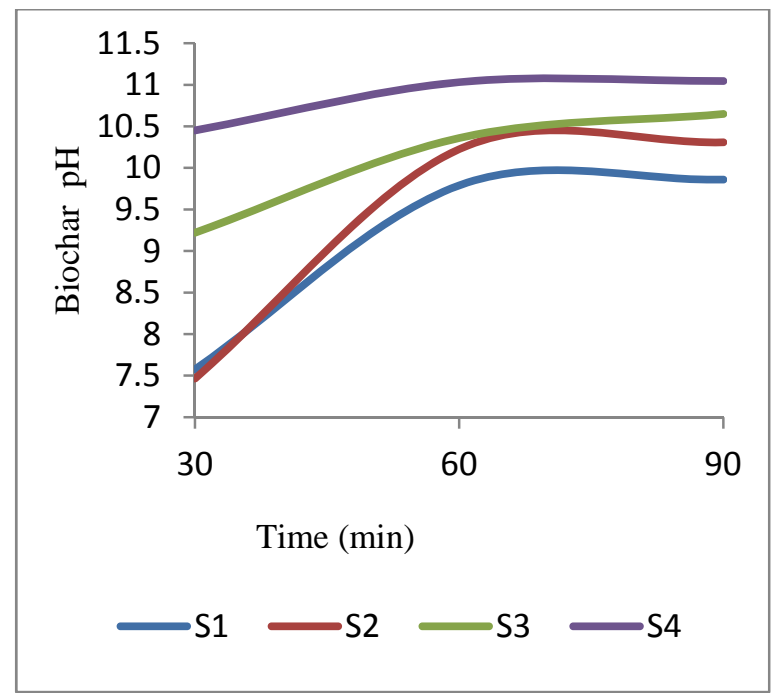

Fig. 12 pH of coffee husk biochar with time.

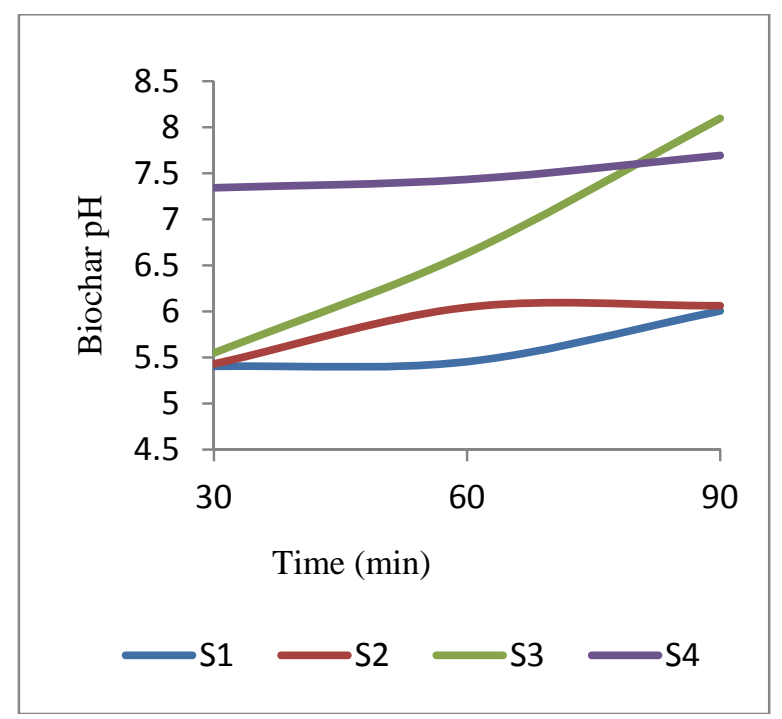

Fig. 13 pH of sawdust biochar with time.

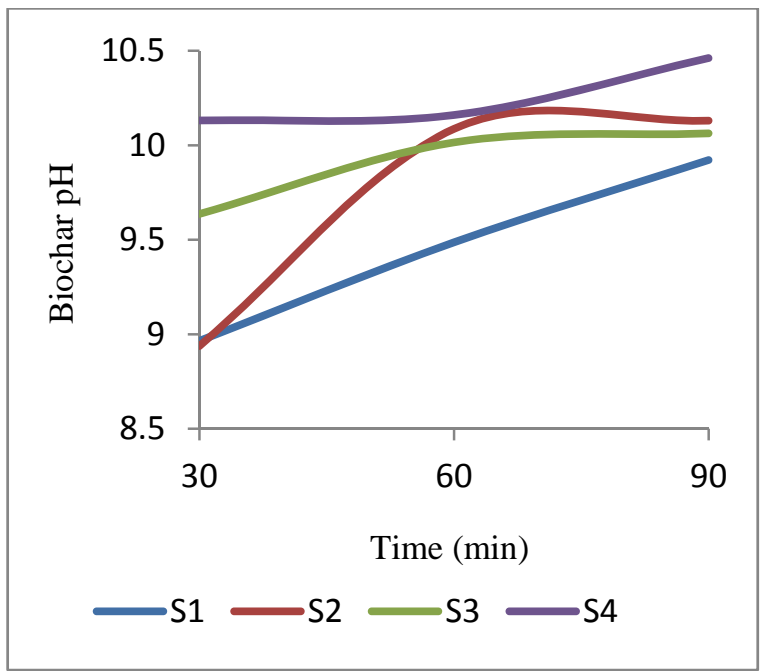

Fig. 14 pH of corncob biochar with time.

\subsection{Biochar $p H$}

It is an indication of the extent, to which the biochar will alter the soil $\mathrm{pH}$, depending on the quantities added. If the $\mathrm{pH}$ of the biochar is lower than that of the soil, it will most likely lower the soil $\mathrm{pH}$, in relation to the quantities applied [38].

The $\mathrm{pH}$ of biochar solution depends on the pyrolysis condition and the type of feedstock [13]. From Figs. 12-14, it was observed that the $\mathrm{pH}$ of the biochar increases with charring time, but because of difference in stove geometry, the rate of increment is also different [21]. Heating with high temperature gave $\mathrm{pH}$ that is more alkaline than that of the low temperature heating case [19].

Due to the difference in feedstocks, the $\mathrm{pH}$ of the biochar made of sawdust was more acidic than the other two. Comparing corncob and sawdust biochar, more prolysis gas was noticed in sawdust biochar, which makes the $\mathrm{pH}$ low [39]. The acidity was confirmed by the presence of negatively charged hard Lewis ligand functional groups in the char, such as carboxyl groups [40].

The relative increase of ash content in the biochar at more pyrolysis conditions (higher heating temperature and time) was another contributing factor to the rise in $\mathrm{pH}$ [41].

From the statistical analysis (Table 2), ANOVA test 
showed that all the parameters significantly affectedthe $\mathrm{pH}$. With respect to biomass, coffee husk and corncob displayed almost same $\mathrm{pH}$, but that of sawdust significantly differ. With respect to time, $\mathrm{pH}$ significantly changed from 8.01 to 8.89 between 30 min and $60 \mathrm{~min}$ charring time. After $60 \mathrm{~min}$, the change was not significant, this may be because of the release of volatile gas before $1 \mathrm{~h}$.

With respect to stove designs, S1 and S2 have similar $\mathrm{pH}$, showing a significant difference from the other stove, especially S4. This may be because of the different height and diameter of the stove.

\subsection{Biochar Surface Area}

Increasing the surface area of a substance generally increases the rate of a chemical reaction [42]. The ensuing carbonization step at high temperature was detrimental to the development of a porous structure in the biochar [43, 44]. Surface area and pore volume may change upon contact with soil by pore clogging from sorbed organic and mineral material, or conversely, possibly by mineralization of volatile matter that may be blocking pores. These properties have been shown to change sorption behavior of mineral and organic matter, which in turn may influence energy and pore space available to soil biota [45]. The surface area of soil is an important physical parameter, which controls essential functions of soil fertility, such as water and nutrient holding capacity, aeration and microbial activity [20].

The experimental result shows surface area of biochar was decreasing with time on most of the stoves. There may be completion of the solidification stage within the biochar before $30 \mathrm{~min}$ [46] or possibly due to ash fusion filling micropores [21]. Too high a temperature will damage the development of porous structures in the char and the walls of the pores become so thin that they collapse [33]. This may also be an indication that the rate of pore formation exceeded that of pore destruction, due to pore enlargement and collapse at the earlier stage and then vice versa at the later stage of pyrolysis [47]. It is the phenomenon where micropores become filled with tars (condensed volatiles) and other decomposition products, partially blocking porosity [48]. The longer holding times reduced the char reactivities, which could be explained by thermal annealing as well as the reduction of the surface area as the conversion proceeded [35]. In Fig. 15, surface area of

Table 2 Statistical result of biochar $\mathrm{pH}$.

\begin{tabular}{ll}
\hline Variables & $\mathrm{pH}$ \\
\hline Biomass & \\
\hline Coffee husk & $9.83 \pm 0.19^{\mathrm{a}}$ \\
Sawdust & $6.43 \pm 0.16^{\mathrm{b}}$ \\
Corncob & $9.83 \pm 0.08^{\mathrm{a}}$ \\
\hline LSD (0.05) & 3.40 \\
\hline Time & \\
\hline 30 min & $8.01 \pm 0.30^{\mathrm{b}}$ \\
60 min & $8.89 \pm 0.31^{\mathrm{a}}$ \\
90 min & $9.19 \pm 0.29^{\mathrm{a}}$ \\
\hline LSD $(0.05)$ & 0.88 \\
\hline Stove & \\
\hline S1 & $8.05 \pm 0.36^{\mathrm{c}}$ \\
S2 & $8.30 \pm 0.38^{\mathrm{c}}$ \\
S3 & $8.91 \pm 0.33^{\mathrm{b}}$ \\
S4 & $9.52 \pm 0.29^{\mathrm{a}}$ \\
\hline LSD (0.05) & 0.61 \\
\hline
\end{tabular}

Results are means of 36 observations, except stove is means of 27 observations.

Means \pm standard error with different letters in a column are significantly different from each other at $P<0.05$.

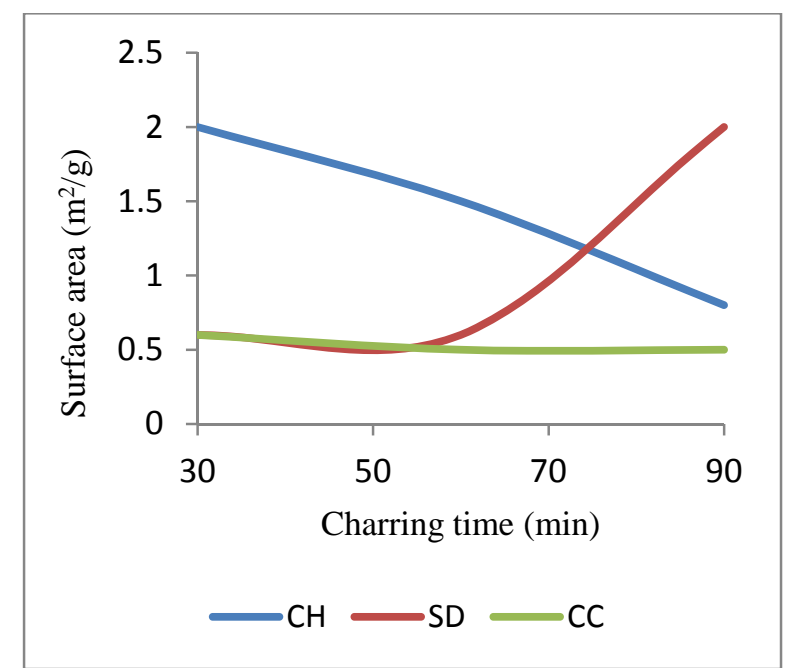

Fig. 15 Surface area of Anila stove produced biochar with time and temperature. 
Table 3 Statistical results of biochar surface area.

\begin{tabular}{ll}
\hline Variables & Surface area $\left(\mathrm{m}^{2} / \mathrm{g}\right)$ \\
\hline Biomass & $2.33 \pm 0.29^{\mathrm{a}}$ \\
\hline Coffee husk & $0.84 \pm 0.12^{\mathrm{b}}$ \\
Sawdust & $0.43 \pm 0.04^{\mathrm{b}}$ \\
Corncob & 1.49 \\
\hline LSD $(0.05)$ & \\
\hline Time & $1.55 \pm 0.39$ \\
\hline 30 min & $1.03 \pm 0.23$ \\
60 min & $1.03 \pm 0.24$ \\
90 min & $\mathrm{NS}$ \\
\hline LSD $(0.05)$ & \\
\hline Stove & $1.46 \pm 0.45$ \\
\hline S1 & $1.29 \pm 0.40$ \\
S2 & $1.04 \pm 0.30$ \\
S3 & $1.01 \pm 0.21$ \\
\hline LS & $\mathrm{NS}$ \\
\hline
\end{tabular}

Results are means of 12 observations, except stove is means of nine observations.

Means \pm standard error with different letters in a column are significantly different from each other at $P<0.05$. NS $=$ not significant.

biochar produced on few stove geometry has a tendency of decreasing and then increasing with time. This may be due to the generation of porosity.

Surface area of biochar produced from all the feedstocks was low $\left(<10 \mathrm{~m}^{2} / \mathrm{g}\right)$ in line with other observations [49].

From Table 3, the ANOVA test shows only biomass significantly affect the surface area of the biochars. Within the biomass, surface area of coffee husk biochar significantly differ from sawdust and corncob biochar. This may be due to the difference in bulk density and void fraction.

\section{Conclusions}

From both simulation and experimental test, it can be concluded that the stove geometry, fuel feed control during operation, heating time and type of biomass are the governing parameters in changing the quality of biochar.

The maximum temperature within the biomass bed is $577^{\circ} \mathrm{C}$ for coffee husk biomass using normal Anila stove, and the maximum outer surface is $271{ }^{\circ} \mathrm{C}$ for corn cob biomass using Cornel stove. The effect of the biomass type and the type of stove design were less in changing the biochar yield, of which the maximum mean was 38.91\% from coffee husk biomass and the minimum mean was $27.11 \%$ from Anila stove. The significant effect of the volatile gas on changing the temperature trend within the biomass bed from the simulation was observed from the deviation between experiment and simulation at longer charring times.

The $\mathrm{pH}$ of biochar is significantly affected by the type of biomass (9.83 mean for corncob and coffee husk, 6.43 mean for sawdust), heating time (9.19 mean for $90 \mathrm{~min}$ and 8.01 mean for $30 \mathrm{~min}$ ) and stove type (9.52 mean for normal Anila and 8.01 mean for Anila continuous feeding flange less). In fact, the type of biomass significantly affects the bulk density and surface area of biochar. Using one stove, charring (after cooking) three times per day, more than 1.15 ton of biochar can be produced per annum with the possibility of 1.45 ton carbon sequestering through the assumption that $70 \%$ is stable for at least 100 years.

Further research would be beneficial for obtaining biochar yield, tar and volatile gas generated at different pyrolysis condition (biomass type, heating temperature and heating time) for specific stove design using pyrolysis modeling and CFD simulation.

\section{Acknowledgments}

The authors thank for Jimma University Institute of Technology, Jimma, Ethiopia, Oromia Agricultural Research Institute, Jimma Agricultural Engineering Research Center, Jimma, Ethiopia, and inputs from professor Johannes Lehmann and his team at Cornell University, USA, as well as Dr. Berhanu Belay at Jimma University, Ethiopia through Biochar Plus Project funded by EU-ACP S\&T II.

\section{References}

[1] Shenbagavalli, S., and Mahimairaja, S. 2012. "Production and Characterization of Biochar from Different Biological Wastes.” International Journal of Plant, Animal and Environmental Sciences 2 (1): 197-201.

[2] Michael, I. B., Christopher, M. W., Pedro, H. D. P. S., 
Nicholas, A. P., and Rocky, D. 2012. "Algal Biochar: Effects and Applications.” GCB Bioenergy 4 (1): 61-9.

[3] Laird, D. A., Brown, R. C., Amonette, J. E., and Lehmann, J. 2009. "Review of the Pyrolysis Platform for Coproducing Bio-oil and Biochar.” Biofuels, Bioproducts and Biorefining 3 (5): 547-62.

[4] Masulili, A., Utomo, W. H., and Syechfani, M. S. 2010. "Rice Husk Biochar for Rice Based Cropping System in Acid Soil: Part 1, The Characteristics of Rice Husk Biochar and Its Influence on the Properties of Acid Sulfate Soils and Rice Growth in West Kalimantan, Indonesia.” Journal of Agricultural Science 2 (1): 39-47.

[5] Steiner, C., Glaser, B., Teixeira, W. G., Lehmann, J., Blum, W. E. H., and Zech, W. 2008. "Nitrogen Retention and Plant Uptake on a Highly Weathered Central Amazonian Ferralsol Amended with Compost and Charcoal.” Plant Nutrition and Soil Science 171 (6): 893-9.

[6] Clough, T. J., Condron, L. M., Kammann, C., and Muller, C. 2013. "A Review of Biochar and Soil Nitrogen Dynamics.” Agronomy 3 (2): 275-93.

[7] Angst, T. E., and Sohi, S. P. 2013. "Establishing Release Dynamics for Plant Nutrients from Biochar.” GCB Bioenergy 5 (2): 221-6.

[8] Basso, A. S., Miguez, F. E., Laird, D. A., Horton, R., and Westgate, M. 2013. "Assessing Potential of Biochar for Increasing Water-Holding Capacity of Sandy Soils.” GCB Bioenergy 5 (2): 132-43.

[9] Shenbagavalli, S., and Mahimairaja, S. 2012. "Characterization and Effect of Biochar on Nitrogen and Carbon Dynamics in Soil.” International Journal of Advanced Biological Research 2 (2): 249-55.

[10] Deal, C., Brewer, C. E., Brown, R. C., Okure, M. A. E., and Amoding, A. 2012. "Comparison of Kiln-Derived and Gasifier-Derived Biochars as Soil Amendments in the Humid Tropics.” Biomass and Bioenergy 37: 161-8.

[11] Lugato, E., Vaccari, F. P., Genesio, L., Baronti, S., Pozzi, A., Rack, M., Woods, J., Simonetti, G., Montanarella, L., and Miglietta, F. 2013. "An Energy-Biochar Chain Involving Biomass Gasification and Rice Cultivation in Northern Italy.” GCB Bioenergy 5 (2): 192-201.

[12] Cornelissen, G., Martinsen, V., Shitumbanuma, V., Alling, V., Breedveld, G. D., Rutherford, D. W., Sparrevik, M., Hale, S. E., Obia, A., and Mulder, J. 2013. "Biochar Effect on Maize Yield and Soil Characteristics in Five Conservation Farming Sites in Zambia." Agronomy 3 (2): 256-74.

[13] Novak, J. M., Lima, I., Xing, B. S., Gaskin, J. W., Steiner, C., Das, K. C., Ahmedna, M., Rehrah, D., Watts, D. W., Busscher, W. J., and Harry, S. 2009. "Characterization of Designer Biochar Produced at Different Temperatures and Their Effects on a Loamy Sand." Annals of
Environmental Science 3 (2): 195-206.

[14] Stewart, C. E., Zheng, J. Y., Botte, J., and Cotrufo, M. F. 2013. "Co-generated Fast Pyrolysis Biochar Mitigates Green-House Gas Emissions and Increases Carbon Sequestration in Temperate Soils.” GCB Bioenergy 5 (2): 153-64.

[15] Crombie, K., Mašek, O., Sohi, S. P., Brownsort, P., and Cross, A. 2013. "The Effect of Pyrolysis Conditions on Biochar Stability as Determined by Three Methods.” GCB Bioenergy 5 (2): 122-31.

[16] Noor, N. M., Shariff, A., and Abdullah, N. 2012. "Slow Pyrolysis of Cassava Wastes for Biochar Production and Characterization." Iranica Journal of Energy and Environment 3: 60-5.

[17] Shafie, S. T., Salleh, M. A., Hang, L. L., Rahman, M., and Ghani, W. A. W. A. K. 2012. "Effect of Pyrolysis Temperature on the Biochar Nutrient and Water Retention Capacity.” Purity, Utility Reaction and Environment 1 (6): 323-37.

[18] Sanger, S. H., Mohod, A. G., Khandetode, Y. P., Shrirame, H. Y., and Deshmukh, A. S. 2011. "Study of Carbonization for Cashew Nut Shell.” Research Journal of Chemical Sciences 1 (2): 43-55.

[19] Devi, P., and Saroha, A. K. 2013. "Effect of Temperature on Biochar Properties during Paper Mill Sludge Pyrolysis.” Inter. J. Chem. Tech. Research 5 (2): 682-7.

[20] Mukherjee, A., and Lal, R. 2013. "Biochar Impacts on Soil Physical Properties and Greenhouse Gas Emissions.” Agronomy 3 (2): 313-39.

[21] Ronsse, F., Van Hecke, S., Dickinson, D., and Prins, W. 2013. "Production and Characterization of Slow Pyrolysis Biochar: Influence of Feedstock Type and Pyrolysis Conditions.” GCB Bioenergy 5: 104-15.

[22] Batra, D., and Rao, T. R. 2000. "Analysis of an Annular Finned Pyrolyser-II.” Energy Conversion and Management 41 (6): 573-83.

[23] Dewangan, K. K., Panwar, A., and Sharma, N. K. 2013. "A Prediction of Effective Thermal Conductivity of Polyester Composites Filled with Micro-sized Rice Husk Particles.” International Journal of Recent Advances in Engineering and Technology 1 (3): 1-8.

[24] De Kam, M. J., Morey, R. V., and Tiffany, D. G. 2009. "Biomass Integrated Gasification Combined Cycle for Heat and Power at Ethanol Plants.” Energy Conversion and Management 50 (7): 1682-90.

[25] Pinto, J., Cruz, D., Paiva, A., Pereira, S., Tavares, P., Fernandes, L., and Varum, H. 2012. "Characterization of Corncob as a Possible Raw Building Material.” Construction and Building Materials 34: 28-33.

[26] Ravi, M. R., Jhalani, A., Sinha, S., and Ray, A. 2004. "Development of a Semi-empirical Model for Pyrolysis of an Annular Sawdust Bed." Journal of Analytical and 
Applied Pyrolysis 71 (1):353-74.

[27] Rajkovich, S., Enders, A., Hanley, K., Hyland, C., Zimmerman, A. R., and Lehmann, J. 2012. "Corn Growth and Nitrogen Nutrition after Additions of Biochars with Varying Properties to a Temperate Soil.” Biology and Fertility of Soils 48 (3): 271-84.

[28] Yadav, S., Tyagi, D. K., and Yadav, O. P. 2011. "Equilibrium and Kinetic Studies on Adsorption of Aniline Blue from Aqueous Solution onto Rice Husk Carbon.” International Journal of Chemistry Research 2 (3): 59-64.

[29] Tanoue, K., Suetomi, T., Uemura, Y., Nishimura, T., Taniguchi, M., and Sasauchi, K. 2013. "Effect of Tar Decomposition on Gas Generation during Pyrolysis in Packed Bed of Woody Biomass.” International Journal of Biomass and Renewables 2 (2): 1-6.

[30] Blasi, C. D., Branca, C., Lombardi, V., Ciappa, P., and Giacomo, C. D. 2013. "Effects of Particle Size and Density on the Packed-Bed Pyrolysis of Wood.” Energy and Fuels 27 (11): 6781-91.

[31] Blasi, C. D., Branca, C., Masotta, F., and Biase, E. D. 2013. "Experimental Analysis of Reaction Heat Effects during Beech Wood Pyrolysis.” Energy and Fuels 27 (5): 2665-74.

[32] Jahirul, M. I., Rasul, M. G., Chowdhury, A. A., and Ashwath, N. 2012. "Biofuels Production through Biomass Pyrolysis-A Technological Review.” Energies 5 (12): 4952-5001.

[33] Paethanom, A., and Yoshikawa, K. 2012. "Influence of Pyrolysis Temperature on Rice Husk Char Characteristics and Its Tar Adsorption Capability.” Energies 5 (12): 4941-51.

[34] Chan, K., and Xu, Z. 2009. "Biochar: Nutrient Properties and Their Enhancement.” In Biochar for Environmental Management: Science and Technology, edited by Lehmann, J., and Joseph, S. London and Sterling: Earthscan, 74.

[35] Wannapeera, J., Worasuwannarak, N., and Pipatmanomai, S. 2008. "Product Yields and Characteristics of Rice Husk, Rice Straw and Corncob during Fast Pyrolysis in a Drop-Tube/Fixed-Bed Reactor.” Songklanakarin Journal of Science and Technology 30 (3): 393-404.

[36] Natarajan, E., and Ganapathy, S. E. 2009. "Pyrolysis of Rice Husk in a Fixed-Bed Reactor.” World Academy of Science, Engineering and Technology 56 (32): 504-8.

[37] Devi, P., and Saroha, A. K. 2014. "Optimization of Pyrolysis Conditions to Synthesize Adsorbent from Paper Mill Sludge.” J. Clean Energy Technologies 2 (2): 180-2.

[38] Glaser, B., Lehmann, J., and Zech, W. 2002. "Ameliorating Physical and Chemical Properties of
Highly Weathered Soils in the Tropics with Charcoal-A Review.” Biology and Fertility of Soils 35 (4): 219-30.

[39] Oladeji, J. T. 2010. "Investigations into Pyrolysis of Few Selected Agro-Residues Commonly Found in Nigeria.” The Pacific Journal of Science and Technology 11 (2): 450-4.

[40] Carrier, M., Hardie, A. G., Uras, U., Gorgens, J., and Knoetze, J. 2012. "Production of Char from Vacuum Pyrolysis of South African Sugar Cane Bagasse and Its Characterization as Activated Carbon and Biochar.” Journal of Analytical and Applied Pyrolysis 96: 24-32.

[41] Enders, A., Hanley, K., Whitman, T., Joseph, S., and Lehmann, J. 2012. "Characterization of Biochars to Evaluate Recalcitrance and Agronomic Performance.” Bioresource Technology 114: 644-53.

[42] Demirbas, A. 2004. "Effects of Temperature and Particle Size on Bio-char Yield from Pyrolysis of Agricultural Residues.” Analytical and Applied Pyrolysis 72 (2): 243-8.

[43] Basu, P. 2010. "Gasification Theory and Modeling of Gasifier.” In Biomass Gasification and Pyrolysis: Practical Design. Oxford, UK: Elsevier Inc., 146-8.

[44] Sukiran, M. A., Kheang, L. S., Bakar, N. A., and Mayu, C. Y. 2011. "Production and Characterization of Biochar from the Pyrolysis of Empty Fruit Bunches.” American Journal of Applied Sciences 8 (10): 984-8.

[45] Lehmann, J., Rillig, M. C., Thies, J., Masiello, C. A., Hockaday, W. C., and Crowley, D. 2011. "Biochar Effects on Soil Biota-A Review.” Soil Biology and Biochemistry 43 (9): 1812-36.

[46] Dufour, A., Castro-Diaz, M., Marchal, P., Brosse, N., Olcese, R., Bouroukba, M., and Snape, C. 2012. "In Situ Analysis of Biomass Pyrolysis by High Temperature Rheology in Relations with ${ }^{1} \mathrm{H}$ NMR.” Energy and Fuels 26 (10): 6432-41.

[47] Ghani, W. A. W. A. K., Mohd, A., Silva, G., Bachmann, R. T., Taufiq-Yap, Y. H., Rashid, U., and Al-Muhtaseb, A. H. 2013. "Biochar Production from Waste Rubber-Wood-Sawdust and Its Potential Use in C Sequestration: Chemical and Physical Characterization.” Industrial Crops and Products 44: 18-24.

[48] Ghani, W. A. W. A. K., and Silva, G. 2014. "Sawdust-Derived Biochar: Characterization and $\mathrm{CO}_{2}$ Adsorption/Desorption Study.” Journal of Applied Sciences 14 (13): 1450-4.

[49] Brewer, C. E., Chuang, V. J., Masiello, C. A., Gonnermann, H., Gao, X. D., Dugan, B., Driverc, L. E., Panzacchi, P., Zygourakisb, K., and Davies, C. A. 2014. "New Approaches to Measuring Biochar Density and Porosity.” Biomass and Bioenergy 66: 176-85. 